\title{
Characterization of the aminopyridine derivative KRC-180 as a JAK2 inhibitor
}

\author{
KYOUNG BIN YOON $^{1}$, SUNG YUN CHO ${ }^{2}$, SU JIN AN ${ }^{1}$, KYEONG RYANG PARK $^{1}$, \\ HYO JEONG LEE ${ }^{1}$, HAE SUNG YOON ${ }^{1}$, SUN-MI LEE ${ }^{3}$, YONG-CHUL KIM ${ }^{3}$ and SUN-YOUNG HAN ${ }^{1}$ \\ ${ }^{1}$ College of Pharmacy and Research Institute of Pharmaceutical Sciences, Gyeongsang National University, Jinju, \\ Gyeongnam 52828; ${ }^{2}$ Bio-organic Science Division, Korea Research Institute of Chemical Technology, Daejeon 34114; \\ ${ }^{3}$ School of Life Sciences, Gwangju Institute of Science \& Technology, Gwangju 61005, Republic of Korea
}

Received May 30, 2016; Accepted March 7, 2017

DOI: $10.3892 / \mathrm{ol} .2017 .6353$

\begin{abstract}
Janus kinase 2 (JAK2) is a non-receptor tyrosine kinase that regulates the signal transducer and activator of transcription (STAT) signaling pathway. Deregulation of JAK2 signaling has previously been observed in hematologic malignancies, including erythroleukemia. In the present study, an aminopyridine derivative compound, KRC-180, exhibited direct inhibition of the JAK2 protein at the catalytic site, as demonstrated using in vitro kinase activity assays and docking analyses. In addition, KRC-180 reduced the phosphorylation of STAT3 and STAT5, downstream signaling molecules of JAK2. The growth of HEL92.1.7 erythroleukemia cells harboring a constitutively activated form of JAK2 was suppressed by KRC-180 treatment; KRC-180 induced apoptotic cell death and cell cycle arrest. The results of the present study indicate that $\mathrm{KRC}-180$ is a JAK2 inhibitor with anti-leukemic properties.
\end{abstract}

\section{Introduction}

Janus kinase 2 (JAK2) belongs to the non-receptor tyrosine kinase JAK family, which is composed of four kinases: JAK1, JAK2, JAK3 and TYK2. JAK kinases transduce signals from cytokine receptors to members of the signal transducer and activator of transcription (STAT) protein family, including STAT3 and STAT5 (1). The JAK/STAT signaling pathway regulates various physiological processes, including proliferation and differentiation (1).

A previous study identified the JAK2 valine-617-phenylalanine $(\mathrm{V} 617 \mathrm{~F})$ mutation in a significant proportion of patients with myeloproliferative neoplasms (MPNs) (2). The mutation resulted in a gain of function for JAK2 and is located in the

Correspondence to: Dr Sun-Young Han, College of Pharmacy and Research Institute of Pharmaceutical Sciences, Gyeongsang National University, 501 Jinju-daero, Jinju, Gyeongnam 52828, Republic of Korea

E-mail: syhan@gnu.ac.kr

Key words: Janus kinase 2, signal transducer and activator of transcription, KRC-180, leukemia
JH2 domain, a pseudokinase domain involved in the autoinhibition of JAK2 activity (3). The JAK2-V617F mutation and other constitutively active forms of JAK2 were also identified in hematological malignancies as an infrequent event $(4,5)$, as reviewed by Furqan et al (6). Small molecule JAK2 inhibitors, including AZD1480, CYT387, SB1518 (pacritinib), INCB16562 and WP1066, have demonstrated preclinical effects in various types of tumors, including leukemia, multiple myeloma, prostate cancer, gastric cancer and neuroblastoma (7-12). The aminopyridine derivative compound KRC-180, in which the aminopyridine group is substituted with benzoxazole, is a small molecule that inhibits c-Met and exhibits a good structure-activity relationship (13). The current study examined the efficacy of KRC-180 as a JAK2 inhibitor and an antiproliferative agent in leukemic cells.

\section{Materials and methods}

Cell culture. The HEL92.1.7 human erythroleukemia cell line was purchased from the American Type Culture Collection (Manassas, VA, USA). The cells were cultured in RPMI 1640 medium (Sigma-Aldrich; Merck KGaA, Darmstadt, Germany) supplemented with $10 \%$ fetal bovine serum (HyClone; GE Healthcare Life Sciences, Logan, UT, USA) and $1 \%$ penicillin/streptomycin The cultured cells were incubated at $37^{\circ} \mathrm{C}$ in an atmosphere containing $5 \% \mathrm{CO}_{2}$.

For the cytotoxicity assay, the cells were seeded into a 96-well plate (10,000 cells/well) and incubated with KRC-180 (synthesized at Korea Research Institute of Chemical Technology, Daejeon, Korea) for $72 \mathrm{~h}$ at $37^{\circ} \mathrm{C}$. KRC-180 was three-fold serially diluted in DMSO to create a 10-point curve at a starting concentration of $100 \mu \mathrm{M}$. As a negative control, the cells were treated with dimethyl sulfoxide. Cell viability was evaluated using a tetrazolium-based assay with an EZ-Cytox Cell Viability Assay kit (no. EZ-12000; Daeil Lab Service Co., Ltd., Seoul, Korea), according to the manufacturer's protocol. The concentration that inhibits growth by $50 \%\left(\mathrm{GI}_{50}\right)$ was calculated by nonlinear regression using GraphPad Prism software (version 5.01; GraphPad Software, Inc., La Jolla, CA, USA) (14).

For drug combination studies, the cells into a 96-well plate (10,000 cells/well) were treated with KRC-180, cytarabine (also 
known as AraC; no. C6645; Sigma-Aldrich; Merck KGaA) and a combination of KRC-180 and AraC. The cells were treated with graded concentrations of $\mathrm{AraC}(0.0025,0.05,0.01,0.02$, $0.04,0.08,0.16,0.32,0.64$ and $1.28 \mu \mathrm{M}), \mathrm{KRC}-180(0.1875$, $0.375,0.75,1.5,3,6,12,24,48$ and $96 \mu \mathrm{M})$, or a combination of AraC and KRC-180 (ratio 1:75) for $72 \mathrm{~h}$. Cell viability was measured and the combination index (CI) was analyzed using CompuSyn software (version 1.0; ComboSyn, Inc., Paramus, NJ, USA), as previously described by Chou (15).

In vitro kinase assay. The inhibition of JAK2 recombinant kinase activity was measured using homogeneous, time-resolved fluorescence (HTRF) assays. Recombinant proteins containing the JAK2 kinase domain were purchased from EMD Millipore (Billerica, MA, USA). Optimal enzyme, ATP and substrate concentrations were established using an HTRF KinEASE kit (no. 62TK0PEB; Cisbio Bioassays, Codolet, France), according to the manufacturer's protocol. Test compounds are three-fold serially diluted in DMSO to create a 10 -point curve at a starting concentration of $100 \mu \mathrm{M}$. The enzymes were mixed with serially diluted compounds and $0.1 \mu \mathrm{M}$ peptide substrates in a kinase reaction buffer [50 mM HEPES (pH 7.0), $10 \mu \mathrm{M}$ ATP, $0.1 \mathrm{mM}$ sodium orthovanadate, $5 \mathrm{mM} \mathrm{MgCl}_{2}, 1 \mathrm{mM}$ DTT, $0.01 \%$ bovine serum albumin (BSA; Gibco; Thermo Fisher Scientific, Inc., Waltham, MA, USA), $0.02 \% \mathrm{NaN}_{3}$ ]. Following the addition of reagents for detection, the time-resolved fluorescence energy transfer (TR-FRET) signal was measured using a VICTOR ${ }^{\mathrm{TM}}$ X5 2030 multilabel plate reader (PerkinElmer, Inc., Waltham, MA, USA). The half maximal inhibitory concentration $\left(\mathrm{IC}_{50}\right)$ was calculated by nonlinear regression using GraphPad Prism software. KRC-180 and its derivatives were synthesized at the Korea Research Institute of Chemical Technology (Daejeon, Korea) as previously described (16).

Molecular docking. The molecular docking procedure was performed using CDOCKER interfaced with BIOVIA Discovery Studio (version 3.5; BIOVIA ${ }^{\mathrm{TM}}$ Corp; Dassault Systèmes, San Diego, CA, USA). The high resolution (2.30 Å) crystal structure of human JAK2 in complex with an inhibitor, N-[1-(3-chlorophenyl)-3-methyl-1H-pyrazol-5-yl] pyrazolo [1,5-a] pyrimidine-3-carboxamide, was downloaded from the RCSB Protein Data Bank (PDB code: 4HGE) (17). For protein preparation, the active site for docking was identified from the binding site of the inhibitor in the co-crystal structure. Following the removal of the inhibitor, water molecules were removed, hydrogen atoms were added and incomplete residues of the side chain were corrected. Subsequently, the energy minimization of the protein structure was achieved by the CHARMM force field of Discovery Studio (version 41; Dassault Systems BIOVIA Corporation, San Diego, CA, USA). For ligand preparation, energy minimization was performed for the generation of 3-D conformers of KRC-180 with the Smart Minimizer algorithm in the CHARMM force field. The original inhibitor of the X-ray co-crystal structure was used as a reference compound to verify the docking protocol, exhibiting a similar binding mode compared with the original complex structure.

Flow cytometry analysis. The HEL92.1.7 cells were cultured in 6-well plates $\left(1 \times 10^{6}\right.$ cells/well) and treated with $0,1,5$ and
$10 \mu \mathrm{M} \mathrm{KRC}-180$ at $37^{\circ} \mathrm{C}$ for $24 \mathrm{~h}$. The cells were fixed with $4 \%$ formalin at room temperature and treated with RNase A $(4 \mathrm{mg} / \mathrm{ml})$ at room temperature. The cells were then stained with propidium iodide (PI; Sigma-Aldrich; Merck KGaA) and subjected to flow cytometry using a BD Accuri ${ }^{\mathrm{TM}}$ C6 flow cytometer (BD Biosciences, San Jose, CA, USA). The data were analyzed using BD Accuri ${ }^{\mathrm{TM}}$ C6 software version 1.0.264.21 (BD Biosciences). For Annexin V staining (18), the cells were seeded in 6 -well plates $\left(1 \times 10^{6}\right.$ cells/well $)$ and treated with $0,1,5$ or $10 \mu \mathrm{M} \mathrm{KRC}-180$ for $48 \mathrm{~h}$ at $37^{\circ} \mathrm{C}$. The cells were then stained using an Alexa Fluor ${ }^{\circledR} 488$ Annexin V/Dead Cell Apoptosis kit (Thermo Fisher Scientific, Inc.), according to the manufacturer's protocol and subjected to flow cytometry.

Immunoblotting. HEL92.1.7 cells were lysed with SDS lysis buffer (12 mM Tris-Cl, pH 6.8, 5\% glycerol, 0.4\% SDS; USB Corporation, Cleveland, OH, USA) and subjected to electrophoresis on 10\% SDS-PAGE. Polyvinylidene fluoride (PVDF) membranes (EMD Millipore) were blocked in Tris-buffered saline (10 mM Tris-Cl, pH 7.4 and $140 \mathrm{mM} \mathrm{NaCl}$; Bioneer Corporation, Daejeon, Korea) containing 0.1\% Tween-20 (TBST) and 5\% nonfat dry milk or BSA. The membranes were then incubated with blocking solution containing the indicated antibodies for $1 \mathrm{~h}$ at room temperature. After washing three times in TBST, the membranes were incubated with goat anti-rabbit IgG (no. 111-035-003; dilution, 1:5,000) and anti-mouse IgG (no. 115-035-033; dilution, 1:5,000) secondary antibodies were purchased from Jackson ImmunoResearch Laboratories, Inc., (West Grove, PA, USA) and conjugated with horseradish peroxidase for $30 \mathrm{~min}$ at room temperature. The blots were washed three times and developed using Amersham $^{\mathrm{TM}}$ ECL Select ${ }^{\mathrm{TM}}$ Western Blotting Detection Reagent (GE Healthcare Life Sciences, Chalfont, UK), and the luminescent signals were visualized using the ImageQuant ${ }^{\mathrm{TM}}$ LAS 4000 mini (GE Healthcare Life Sciences). Antibodies against phospho-JAK2 [p-JAK2; rabbit monoclonal immunoglobulin G (IgG); no. 3776; dilution, 1:1,000], p-STAT3 (rabbit polyclonal IgG; no. 9131; dilution, 1:1,000), p-STAT5 rabbit polyclonal IgG; no. 9351; dilution, 1:1,000) and poly (ADP ribose) polymerase (PARP; rabbit polyclonal IgG; no. 9542; dilution, 1:1,000) were purchased from Cell Signaling Technology, Inc. (Danvers, MA, USA). Antibodies against JAK2 (rabbit polyclonal IgG; no. sc-278; dilution, 1:1,000), STAT3 (rabbit polyclonal IgG; no. sc-482; dilution, 1:1,000) and STAT5 (rabbit polyclonal IgG; no. sc-835; dilution, 1:1,000) were from Santa Cruz Biotechnology, Inc. (Dallas, TX, USA). Goat anti-rabbit IgG (no. 111-035-003; dilution, 1:5,000) and anti-mouse IgG (no. 115-035-033; dilution 1:5,000) secondary antibodies were purchased from Jackson ImmunoResearch Laboratories, Inc. (West Grove, PA, USA).

Reverse transcription-polymerase chain reaction ( $R T-P C R)$. The HEL92.1.7 cells were harvested and total RNA was extracted using the ReliaPrep ${ }^{\text {TM }}$ RNA Cell Miniprep System (Promega Corporation, Madison, WI, USA). The cDNA was synthesized using a Maxime RT PreMix kit (Intron Biotechnology, Inc., Seongnam, Korea). The cDNA (1 $\mu \mathrm{g})$ was amplified using 10 pmol primers (Integrated DNA Technologies, Inc., Coralville, IA, USA) in the PCR reaction: $94^{\circ} \mathrm{C}$ for $5 \mathrm{~min}$ followed by 30 cycles at $95^{\circ} \mathrm{C}$ for $30 \mathrm{sec}, 60^{\circ} \mathrm{C}$ for 
Table I. Structure-activity relationship of KRC-180 derivatives.<smiles>[R]c1cnc(N)c(-c2nc3cc([R])c([R])c([R])c3o2)c1</smiles>

\begin{tabular}{|c|c|c|c|c|}
\hline Compound & $\mathrm{R}^{1}$ & $\mathrm{R}^{2}$ & $\mathrm{R}^{3}$ & $\mathrm{JAK}^{2} \mathrm{IC}_{50}(\mu \mathrm{M})$ \\
\hline KRC-180 (1) & $\mathrm{H}$ & $\mathrm{OH}$ & $\mathrm{H}$ & 0.12 \\
\hline 2 & $\mathrm{H}$ & $\mathrm{N}$ & $\mathrm{H}$ & 0.54 \\
\hline 3 & $\mathrm{H}$ & $\mathrm{Cl}$ & $\mathrm{H}$ & 0.77 \\
\hline 4 & $\mathrm{H}$ & $\mathrm{H}$ & $\mathrm{H}$ & 1.79 \\
\hline 5 & $\mathrm{H}$ & $\mathrm{NMe}_{2}$ & $\mathrm{H}$ & 0.4 \\
\hline 6 & $\mathrm{CN}$ & $\mathrm{H}$ & $\mathrm{H}$ & 1.02 \\
\hline 7 & $\mathrm{H}$ & $\mathrm{OSO}_{2} \mathrm{Me}$ & $\mathrm{H}$ & 0.17 \\
\hline 8 & $\mathrm{OMe}$ & $\mathrm{H}$ & $\mathrm{H}$ & 0.25 \\
\hline 9 & $\mathrm{CF}_{3}$ & $\mathrm{H}$ & $\mathrm{H}$ & 15.9 \\
\hline 10 & $\mathrm{~F}$ & $\mathrm{H}$ & $\mathrm{OH}$ & 0.81 \\
\hline 11 & $\mathrm{H}$ & $\mathrm{Cl}$ & $\mathrm{F}$ & 4.2 \\
\hline 12 & $\mathrm{CONMe}_{2}$ & $\mathrm{OH}$ & $\mathrm{H}$ & 5.5 \\
\hline 13 & $\mathrm{H}$ & $\mathrm{OPh}$ & $\mathrm{H}$ & 1.1 \\
\hline 14 & $\mathrm{H}$ & $\mathrm{OMe}$ & & 0.25 \\
\hline 15 & $\mathrm{OH}$ & $\mathrm{Me}$ & $\mathrm{H}$ & 0.22 \\
\hline 16 & $\mathrm{H}$ & $\mathrm{OH}$ & $\mathrm{Et}$ & 0.28 \\
\hline 17 & $\mathrm{H}$ & Et & $\mathrm{OH}$ & 2.4 \\
\hline 18 & $\mathrm{H}$ & & $\mathrm{H}$ & 0.31 \\
\hline 19 & $\mathrm{H}$ & $\mathrm{OH}$ & & 1.1 \\
\hline 20 & $\mathrm{H}$ & $\mathrm{Me}$ & $\mathrm{OH}$ & 2.1 \\
\hline 21 & $\mathrm{H}$ & $0-1$ & $\mathrm{H}$ & 0.76 \\
\hline
\end{tabular}

JAK2, Janus kinase 2.

$30 \mathrm{sec}$ and $74^{\circ} \mathrm{C}$ for $90 \mathrm{sec}$. The following primers were used in the study: Elongation factor $1 \alpha$ (forward, 5'-AGGTGA TTATCCTGAACCATCC-3' and reverse, 5'-AAAGGTGGA TAGTCTGAGAAGC-3'; size 234 bp); Cyclin B1 (forward, 5'-AAGAGCTTTAAACTTTGGTCTGGG-3' and reverse, 5'-CTTTGTAAGTCCTTGATTTACCATG-3'; size 319 bp). The PCR products were analyzed by electrophoresis and stained with RedSafe ${ }^{\mathrm{TM}}$ nucleic acid staining solution (iNtRON Biotechnology, Seongnam, Korea) on a $1.5 \%$ agarose gel.
Statistical analysis. The data from the experiments are presented as the mean \pm SEM.

\section{Results}

Structure-activity associations of KRC-180 derivatives. In order to examine the structure-activity associations of KRC-180 derivatives, the in vitro JAK2 kinase inhibitory activities toward a substituent effect on $\mathrm{R}^{1}, \mathrm{R}^{2}$ and $\mathrm{R}^{3}$ positions of the phenyl ring of benzoxazole were examined 
(Table I). In the initial assessment, a $\mu \mathrm{M}$ range of potency was observed with no substitution on the phenyl ring (entry $1, \mathrm{R}^{1}=\mathrm{R}^{2}=\mathrm{R}^{3}=\mathrm{H}$ ). Introduction of simple $\mathrm{CN}, \mathrm{OMe} \mathrm{CF}_{3}$ at $\mathrm{R}^{1}$ position was observed to be detrimental to the activity (compound 6, 8, 9, 12). In particular, the lowest inhibitory activity was observed in the case of $\mathrm{CONMe}_{2}$ at the $\mathrm{R}^{1}$ position, presumably due to steric congestion in the binding pocket of the enzyme (compound 12). Introduction of piperidine, chlorine and $\mathrm{NMe}_{2}$ at the $\mathrm{R}^{2}$ position of phenyl slightly improved the inhibitory activity (compound $2,3,5$ ). Of the substituents, introduction of $\mathrm{OH}$ at the $\mathrm{R}^{2}$ position significantly improved the inhibitory activity. In addition, introduction of sulfate (compound 7) to the $\mathrm{R}^{2}$ position exhibited a similar degree of activity to that of $\mathrm{OH}$ (compound 3). Bulky substituents larger than methylsulfate (compound 7), including phenoxy (compound 13) and pyrazinyloxy (compound 18), did not significantly improve the activity, compared with that of $\mathrm{OH}$. To assess the substituent effect on the $\mathrm{R}^{3}$ position, $\mathrm{OH}$ (compound 10), indazolyl (Table I; compound 14) and pyrazinyloxy (compound 19) were evaluated, and the results were disclosed as detrimental to increasing the inhibitory activity, as the $\mathrm{OH}$ substituent at $\mathrm{R}^{2}$ (compound 1) displayed potent activity, the $\mathrm{OH}$ substituent at $\mathrm{R}^{3}$ (compound 10) and pyrazine-2-oxy (compound 19) exhibited only modest activity and the indazole substituent (compound 14) did not contribute to potentency activity. To improve the inhibitory activity, methyl and ethyl were introduced to the $\mathrm{R}^{1}$ and $\mathrm{R}^{3}$ positions to induce hydrophobic interactions with adjacent hydrophobic groups, but dual substitutions on phenyl did not influence the inhibitory activity (compound 16, 17, 20). When modifying the $\mathrm{R}^{3}$ position with a bulky substituent, such as indazoly (compound 14), the compound exhibited moderate activity compared with that of compound 3; however, the introduction of pyrazinyloxy (compound 19) decreased the inhibitory activity.

Inhibition of JAK2 kinase activity in vitro. The effect of KRC-180 on the kinase activity of the purified recombinant JAK2 protein was measured using the TR-FRET method. KRC-180 markedly inhibited the kinase activity of JAK2 in vitro with an $\mathrm{IC}_{50}$ of $0.123 \mu \mathrm{M}$ (Fig. $1 \mathrm{~A}$ and $\mathrm{B}$ ). The direct interaction between JAK2 and KRC-180 in the docking analysis is presented in Fig. 1C. A co-crystal protein structure of JAK2 and a pyrazolopyrimidine-based inhibitor was obtained from the protein data bank (PDB code: 4HGE). KRC-180 was fitted into the active site of 4HGE. For example, the hydroxyl benzoxazole moiety is positioned in a hydrophilic site composed of aspartic acid and arginine, as indicated by the region of light blue, and piperidine is located in a hydrophobic pocket, designated in light gray. CDOCKER interaction energy values for ruxolitinib (JAK1/2 inhibitor used for patients with myelofibrosis) (19) and KRC-180 were $-50.10 \mathrm{kcal} / \mathrm{mol}$ and $-41.83 \mathrm{kcal} / \mathrm{mol}$, respectively.

The current study has demonstrated that KRC-180 has three important $\mathrm{H}$-bonds. First, the oxygen of the $\mathrm{OH}$ group of benzoxazole interacts as an $\mathrm{H}$-bond acceptor to the $\mathrm{NH}$ of the Arg938 residue. Second, the hydrogen of the $\mathrm{OH}$ group acts as a hydrogen bond donor to the $\mathrm{COO}^{-}$carboxylic acid side chain of the Asp939 residue. Finally, the NH group of piperidine forms a hydrogen bond with the backbone
A
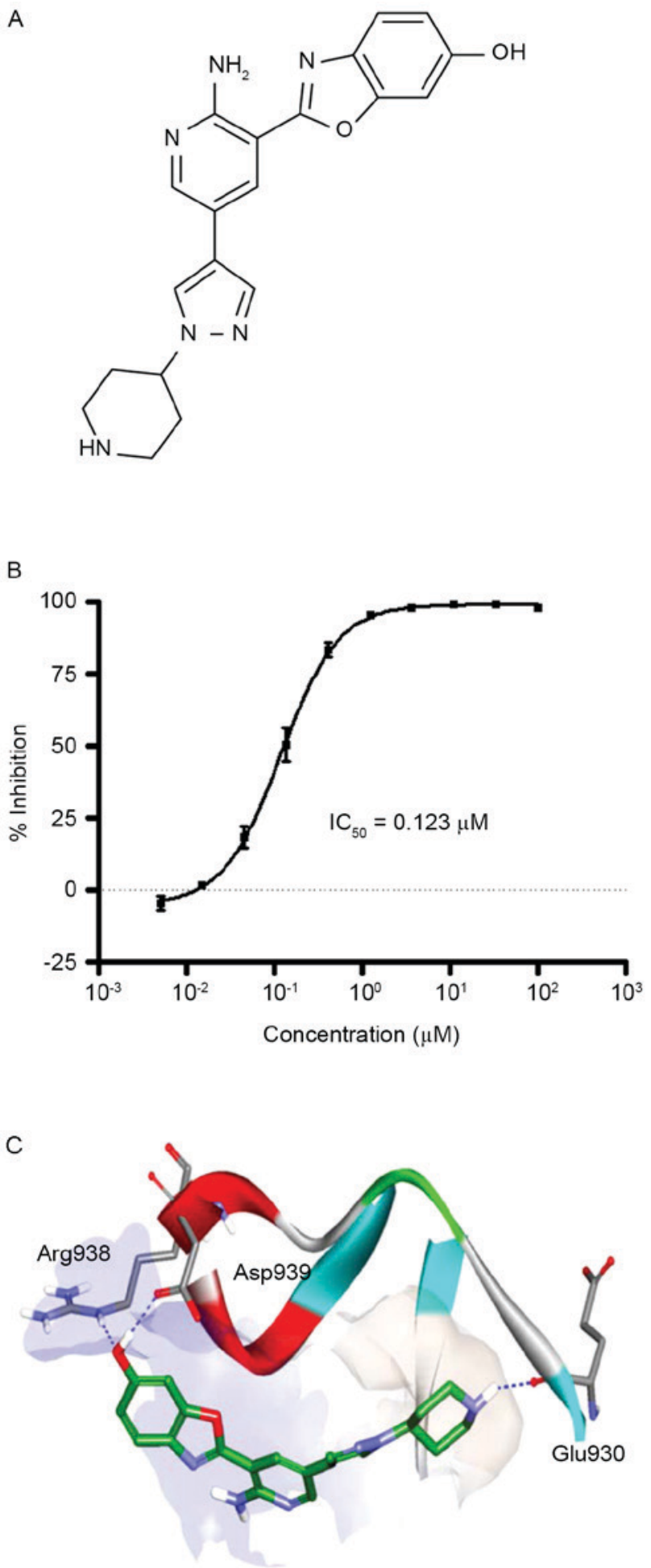

Figure 1. Inhibition of JAK2 kinase activity by KRC-180. (A) Chemical structure of KRC-180. (B) In vitro JAK2 kinase activity. The indicated concentrations of KRC-180 were added to purified JAK2 enzyme and the kinase activity was measured using time-resolved fluorescence energy transfer. (C) Docking mode of JAK2 and KRC-180. The crystal structure of JAK2 was taken from the active site of the JAK2 kinase domain (Protein Data Bank entry: 4HGE). The P-loop was removed to allow an improved view of the key interactions with Glu930, Arg938, Asp 939, and KRC-180. JAK2, Janus kinase 2 .

carbonyl group of Glu930. Although piperidine is at a hydrophobic site, the hydrogen bond has a bonding angle of optimum length. 
A

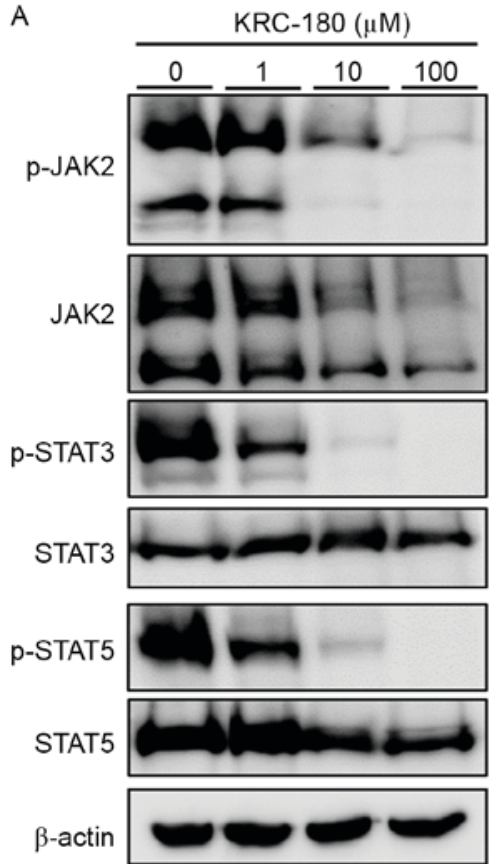

B

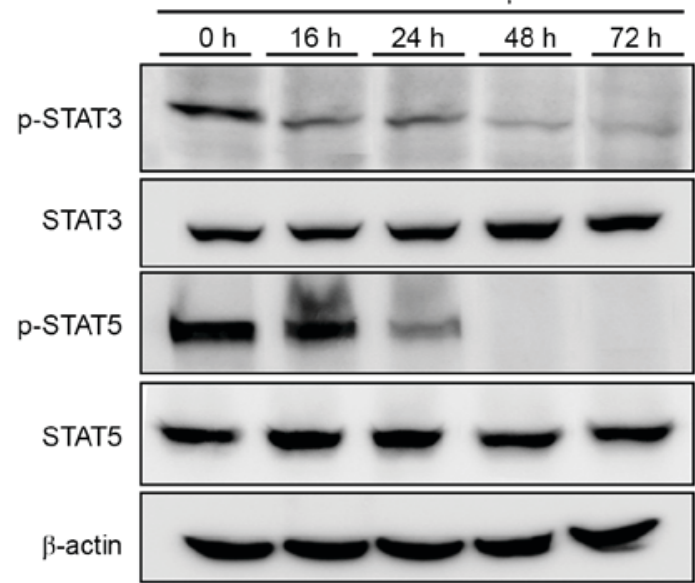

Figure 2. Inhibition of JAK2 phosphorylation in HEL92.1.7 cells. (A) Cells were incubated with the indicated concentrations of KRC-180 for 48 h. (B) The cells were incubated with $10 \mu \mathrm{M}$ KRC-180 for the indicated time. The phosphorylation levels of JAK2, STAT3 and STAT5 were evaluated using western blot analysis with phospho-specific antibodies. The expression levels of total JAK2, STAT3, and STAT5 are also shown. JAK2, Janus kinase 2; STAT, signal transducer and activator of transcription.

KRC-180 inhibits JAK2 phosphorylation in HEL92.1.7 cells. To examine the effect of KRC-180 JAK2 phosphorylation, HEL92.1.7 cells expressing the JAK2 mutant (JAK2-V617F) were used. The JAK2 mutation in HEL92.1.7 cells resulted in the constitutive activation and phosphorylation of JAK2 without stimulation. KRC-180 treatment decreased JAK2 phosphorylation and expression, as demonstrated via western blotting analysis of p-JAK2 and JAK2 (Fig. 2A). Downstream of the JAK2 signaling pathway, STAT5 and STAT3 phosphorylation was also dose-dependently decreased by KRC-180 treatment. Phosphorylation of STAT3 and STAT5 was almost completely diminished following $10 \mu \mathrm{M}$ KRC-180 treatment. The levels of phosphorylated STAT3 and STAT 5 in HEL92.1.7 cells treated with $10 \mu \mathrm{M}$ of KRC-180 for $16 \mathrm{~h}, 24 \mathrm{~h}, 48 \mathrm{~h}$ and $72 \mathrm{~h}$ were analyzed (Fig. 2B). STAT3 and STAT5 phosphorylation was not detected after $48 \mathrm{~h}$. These results indicate that direct kinase inhibition by KRC-180 results in the inhibition of JAK2 activity and its downstream signaling in leukemic cells.

KRC-180 inhibits HEL92.1.7 cell proliferation and induces apoptosis. The effects of KRC-180 on the growth of HEL92.1.7 cells were examined. HEL92.1.7 cell proliferation was suppressed dose-dependently by KRC-180, with a $\mathrm{GI}_{50}$ of $2.69 \mu \mathrm{M}$ (Fig. 3A). The effect of KRC-180 in combination with AraC was investigated. The $\mathrm{GI}_{50}$ ratio of AraC single treatment and KRC-180 single treatment $\left(\mathrm{GI}_{50}\right.$ ratio AraC:KRC-180) against HEL92.1.7 cells was 1:75. The CI calculated by CompuSyn software demonstrated the additive effect of the 1:75 AraC and KRC-180 treatment on cell viability (CI at the $50 \%$ effective dose, $1.05 ; \mathrm{CI}$ at the $75 \%$ effective dose, $1.01 ; \mathrm{CI}$ at the $90 \%$ effective dose, 0.98 ; Fig. 3B).
Apoptosis induction by KRC-180 was also investigated. A dose-dependent increase in the apoptotic cell population was observed with Annexin V/PI staining following KRC-180 treatment (Fig. 3C). In particular, $10 \mu \mathrm{M}$ KRC-180 increased the early apoptotic population from 14-23.6\% (Fig. 3C, upper right quadrant). The dose-dependent increase in PARP cleavage by KRC-180 confirmed that apoptotic cell death is induced by KRC-180 treatment (Fig. 3D).

KRC-180 induces cell cycle arrest at the $G_{2} / M$ phase. The HEL92.1.7 cells were subjected to cell cycle analysis following treatment with KRC-180. KRC-180 treatment from 0.1-10 $\mu \mathrm{M}$ for $24 \mathrm{~h}$ resulted in cell cycle arrest at the $\mathrm{G}_{2} / \mathrm{M}$ phase (Fig. 4A). The cell population in the $\mathrm{G}_{2} / \mathrm{M}$ phase increased with rising concentrations of KRC-180, from $23.3 \%$ (control) to $62.1 \%(10 \mu \mathrm{M} \mathrm{KRC}-180)$. Cyclin $\mathrm{B} 1$ is one of the components required for the cell cycle progression in the $\mathrm{G}_{2} / \mathrm{M}$ phase (20). KRC-180 treatment decreased the expression levels of cyclin B1 mRNA, as demonstrated using RT-PCR (Fig. 4B). The dose-dependent reduction of cyclin B1 expression levels was consistent with cell cycle arrest at the $\mathrm{G}_{2} / \mathrm{M}$ phase following KRC-180 treatment.

\section{Discussion}

In the present study, KRC-180 was characterized as a direct inhibitor of JAK2 with antiproliferative activity in erythroleukemia cells. KRC-180 directly inhibited the activity of JAK2. A previous report demonstrated that KRC-180 also exhibits inhibitory activity against c-Met, Flt3, Ron and Aurora A, indicating that KRC-180 possesses multikinase inhibitory characteristics (13). To evaluate the JAK2-mediated effect of KRC-180 on cell survival, HEL92.1.7 erythroleukemia cells 


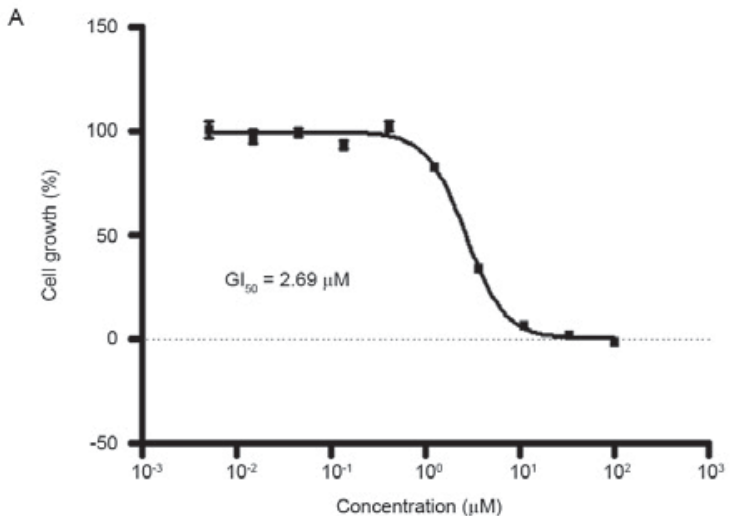

C

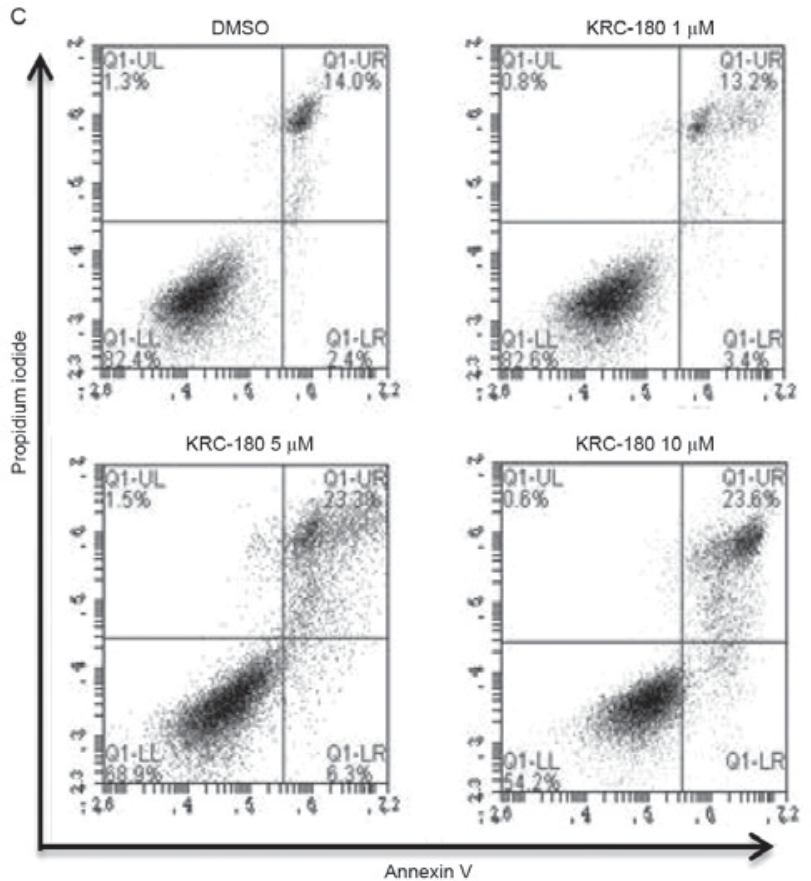

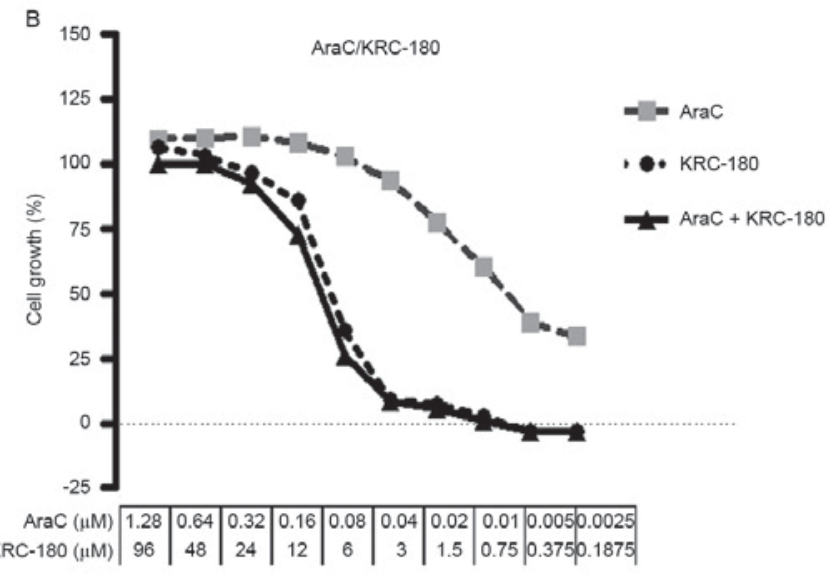

D

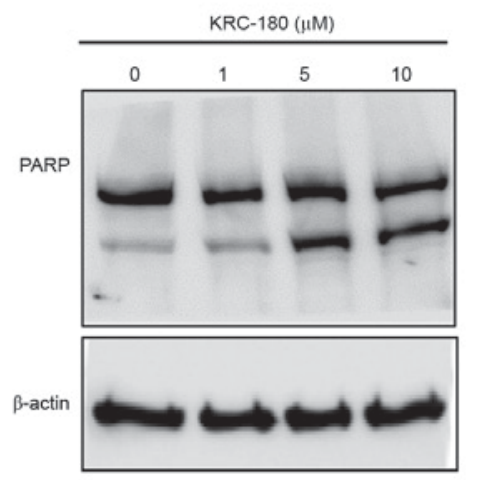

Figure 3. Effect of KRC-180 on HEL92.1.7 cell growth and cell death. (A) The indicated concentrations of KRC-180 were applied for $72 \mathrm{~h}$, and the growth inhibition of HEL92.1.7 cells was measured using a tetrazolium-based cell viability assay. The cell growth (\%) was calculated using $0.5 \%$ dimethyl sulfoxide treatment as a negative control. The $\mathrm{GI}_{50}$ was calculated by nonlinear regression. The data are presented as the mean \pm standard error of the mean of three independent experiments. (B) The cells were treated with graded concentrations of $\mathrm{AraC}(0.0025,0.05,0.01,0.02,0.04,0.08,0.16,0.32,0.64,1.28 \mu \mathrm{M})$, KRC-180 $(0.1875,0.375,0.75,1.5,3,6,12,24,48,96 \mu \mathrm{M})$, or a combination of AraC and KRC-180 (ratio 1:75) for $72 \mathrm{~h}$, and the cell growth was subsequently determined using the cytotoxicity assay. The combination index was calculated using CompuSyn software. (CI value $>1.0$, antagonism; $\mathrm{CI}$ value $=1.0$, additivity; CI value $<1.0$, synergism). (C) The cells were treated with the indicated concentrations of KRC-180 for $48 \mathrm{~h}$. The cells were then stained with propidium iodide/Annexin V and subjected to flow cytometry. (D) The cells were treated with KRC-180 for $24 \mathrm{~h}$ at the indicated concentrations, and cleaved and uncleaved poly (ADP ribose) polymerase was detected using western blot analysis. AraC, cytarabine; $\mathrm{GI}_{50}$, concentration that inhibits growth by $50 \%$.

were used. HEL92.1.7 cells harbor the JAK2-V617F mutation resulting in the constitutive activation of JAK2 and associated downstream signaling. In cells carrying the V617F mutation, cell survival depends on JAK2 signaling (2). Cell cytotoxicity induced by KRC-180 in HEL92.1.7 cells confirms the JAK2-mediated effect of KRC-180.

To investigate the potential of KRC-180 in combination treatment with current leukemic therapies, the CI of KRC-180 and $\mathrm{AraC}$ was measured. A CI value of $\sim 1$ indicates an additive effect of KRC-180 and AraC. Thus, this result provides a basis for the combination therapy of KRC-180 and AraC.

KRC-108 (compound 4 in Table I), a compound structurally similar to KRC-180, has been reported as a multikinase inhibitor with an antitumor effect (21). The presence of the
$\mathrm{OH}$ residue at the benzoxazole ring in $\mathrm{KRC}-180$ is the only difference between KRC-180 and KRC-108, and the $\mathrm{IC}_{50}$ for JAK2 inhibition of KRC-108 is 15 -fold higher than that of KRC-180 (Table I). This suggests that the OH residue on the benzo(d)oxazole ring is important for the inhibition of JAK2 kinase activity. The importance of the hydroxyl residue was confirmed by the docking analysis, which demonstrated an interaction of the $\mathrm{OH}$ residue with the Arg938 and Asp939 residues of the JAK2 protein.

At present, two JAK inhibitors have been approved and clinically used: Ruxolitinib and tofacitinib. Ruxolitinib (formerly known as INCB018424) is indicated for the treatment of myelofibrosis and polycythemia vera, which are types of MPNs (19). Ruxolitinib inhibits JAK1 and JAK2 and clinically 


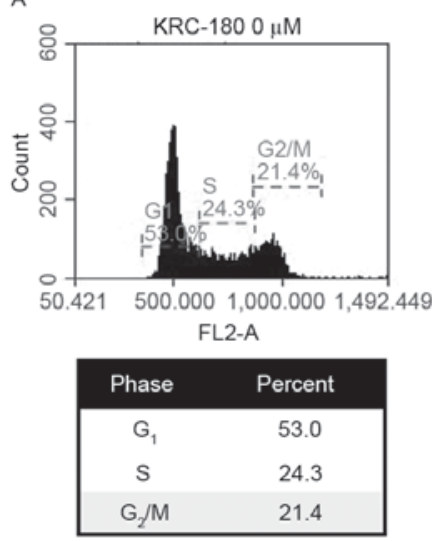

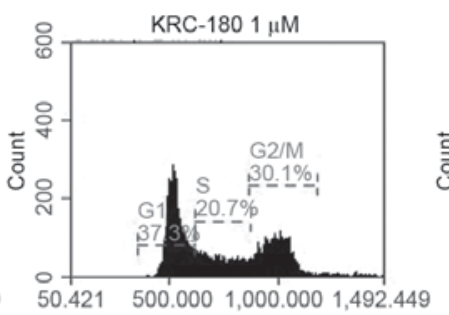
FL2-A

\begin{tabular}{|cc|}
\hline Phase & Percent \\
\hline$G_{1}$ & 37.3 \\
$S$ & 20.7 \\
$G_{2} / M$ & 30.1 \\
\hline
\end{tabular}

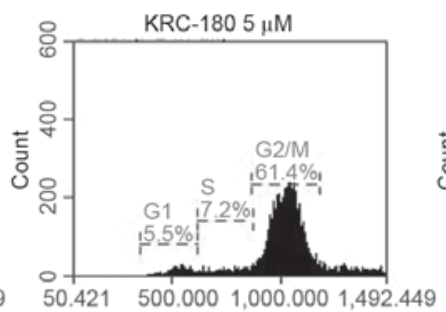

FL2-A

\begin{tabular}{|cc|}
\hline Phase & Percent \\
\hline $\mathrm{G}_{1}$ & 5.5 \\
$\mathrm{~S}$ & 7.2 \\
$\mathrm{G}_{2} / \mathrm{M}$ & 61.4 \\
\hline
\end{tabular}

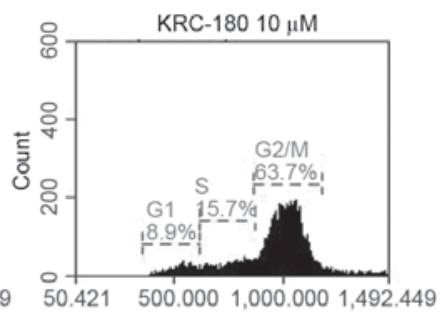

FL2-A

\begin{tabular}{|cc|}
\hline Phase & Percent \\
\hline $\mathrm{G}_{1}$ & 8.9 \\
$\mathrm{~S}$ & 15.7 \\
$\mathrm{G}_{2} / \mathrm{M}$ & 63.7 \\
\hline
\end{tabular}

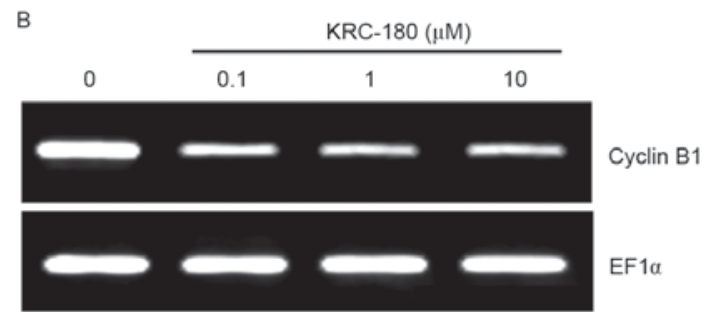

Figure 4. Effect of KRC-180 on the HEL92.1.7 cell cycle. (A) The cells were treated with KRC-180 for 24 h. The cells were stained with propidium iodide and then subjected to cell cycle analysis using flow cytometry. $\mathrm{M} 1: \mathrm{G}_{1}$ phase; $\mathrm{M} 2: \mathrm{S}$ phase; $\mathrm{M} 3: \mathrm{G}_{2} / \mathrm{M}$ phase. (B) The cells were treated with KRC-180 for $16 \mathrm{~h}$ at the indicated concentrations. Total RNA was prepared and reverse transcription-polymerase chain reaction analysis was performed using cyclin B primer pairs. RT-PCR with the elongation factor- $1 \alpha$ primer was used as an internal control.

improves the symptoms associated with MPNs (19). Tofacitinib is used for rheumatoid arthritis with inhibitory activity against JAK3, in addition to JAK1 and JAK2 (22). The clinical development of various small molecules with JAK2-inhibitory activity, which are indicated for MPNs, rheumatoid arthritis and cancer, has been carried out (23). Although certain clinical trials are on hold due to adverse effects (24), the results acquired from these clinical studies will aid with the future development of agents that inhibit JAK2. In the present study, the JAK2-inhibitory activity and antiproliferative effect of KRC-180 was investigated. JAK2 kinase inhibition and downstream signaling pathway suppression resulted in apoptosis and cell cycle arrest. Pharmacological and chemical data from these results may aid the development of novel JAK inhibitors that could then be used to treat cancer.

\section{Acknowledgements}

The present study was supported by grants from the National Research Foundation of Korea (grant no. 2015R1C1A2A01053928) funded by the government of Korea (Ministry of Education, Science and Technology).

\section{References}

1. Schindler C and Darnell JE Jr: Transcriptional responses to polypeptide ligands: The JAK-STAT pathway. Annu Rev Biochem 64: 621-651, 1995.

2. Quintás-Cardama A, Kantarjian H, Cortes J and Verstovsek S: Janus kinase inhibitors for the treatment of myeloproliferative neoplasias and beyond. Nat Rev Drug Discov 10: 127-140, 2011.

3. Saharinen P, Takaluoma K and Silvennoinen O: Regulation of the Jak2 tyrosine kinase by its pseudokinase domain. Mol Cell Biol 20: 3387-3395, 2000
4. Steensma DP, Dewald GW, Lasho TL, Powell HL, McClure RF, Levine RL, Gilliland DG and Tefferi A: The JAK2 V617F activating tyrosine kinase mutation is an infrequent event in both 'atypical' myeloproliferative disorders and myelodysplastic syndromes. Blood 106: 1207-1209, 2005.

5. Lacronique V, Boureux A, Valle VD, Poirel H, Quang CT, Mauchauffé M, Berthou C, Lessard M, Berger R, Ghysdael J and Bernard OA: A TEL-JAK2 fusion protein with constitutive kinase activity in human leukemia. Science 278: 1309-1312, 1997.

6. Furqan M, Mukhi N, Lee B and Liu D: Dysregulation of JAK-STAT pathway in hematological malignancies and JAK inhibitors for clinical application. Biomark Res 1: 5, 2013.

7. Gu L, Liao Z, Hoang DT, Dagvadorj A, Gupta S, Blackmon S, Ellsworth E, Talati P, Leiby B, Zinda M, et al: Pharmacologic inhibition of Jak2-Stat5 signaling By Jak2 inhibitor AZD1480 potently suppresses grow th of both primary and castrate-resistant prostate cancer. Clin Cancer Res 19: 5658-5674, 2013.

8. Hedvat M, Huszar D, Herrmann A, Gozgit JM, Schroeder A, Sheehy A, Buettner R, Proia D, Kowolik CM, Xin H, et al: The JAK2 inhibitor AZD1480 potently blocks Stat3 signaling and oncogenesis in solid tumors. Cancer cell 16: 487-497, 2009.

9. Hart S, Goh KC, Novotny-Diermayr V, Hu CY, Hentze H, Tan YC, Madan B, Amalini C, Loh YK, Ong LC, et al: SB1518, a novel macrocyclic pyrimidine-based JAK2 inhibitor for the treatment of myeloid and lymphoid malignancies. Leukemia 25: 1751-1759, 2011.

10. Scuto A, Krejci P, Popplewell L, Wu J, Wang Y, Kujawski M, Kowolik C, Xin H, Chen L, Wang Y, et al: The novel JAK inhibitor AZD1480 blocks STAT3 and FGFR3 signaling, resulting in suppression of human myeloma cell growth and survival. Leukemia 25: 538-550, 2011.

11. Yan S, Li Z and Thiele CJ: Inhibition of STAT3 with orally active JAK inhibitor, AZD1480, decreases tumor growth in Neuroblastoma and Pediatric Sarcomas In vitro and In vivo. Oncotarget 4: 433-445, 2013.

12. Judd LM, Menheniott TR, Ling H, Jackson CB, Howlett M, Kalantzis A, Priebe W and Giraud AS: Inhibition of the JAK2/STAT3 pathway reduces gastric cancer growth in vitro and in vivo. PLoS One 9: e95993, 2014.

13. Lee J, Han SY, Jung H, Yang J, Choi JW, Chae CH, Park CH, Choi SU, Lee K, Ha JD, et al: Synthesis and structure-activity relationship of aminopyridines with substituted benzoxazoles as c-Met kinase inhibitors. Bioorg Med Chem Lett 22: 4044-4048, 2012. 
14. Chung HJ, Kamli MR, Lee HJ, Ha JD, Cho SY, Lee J, Kong JY and Han SY: Discovery of quinolinone derivatives as potent FLT3 inhibitors. Biochem Biophys Res Commun 445: 561-565, 2014

15. Chou TC: Theoretical basis, experimental design, and computerized simulation of synergism and antagonism in drug combination studies. Pharmacol Rev 58: 621-681, 2006.

16. Cho SY, Han SY, Ha JD, Ryu JW, Lee CO, Jung H, Kang NS, Kim HR, Koh JS and Lee J: Discovery of aminopyridines substituted with benzoxazole as orally active c-Met kinase inhibitors. Bioorg Med Chem Lett 20: 4223-4227, 2010.

17. Hanan EJ, van Abbema A, Barrett K, Blair WS, Blaney J, Chang C, Eigenbrot C, Flynn S, Gibbons P, Hurley CA, et al: Discovery of potent and selective pyrazolopyrimidine janus kinase 2 inhibitors. J Med Chem 55: 10090-11107, 2012.

18. Han MH, Park C, Kwon TK, Kim GY, Kim WJ, Hong SH, Yoo YH and Choi YH: The histone deacetylase inhibitor trichostatin a sensitizes human renal carcinoma cells to TRAIL-induced apoptosis through down-regulation of c-FLIPL. Biomol Ther (Seoul) 23: 31-38, 2015.
19. Vaddi K, Sarlis NJ and Gupta V: Ruxolitinib, an oral JAK1 and JAK2 inhibitor, in myelofibrosis. Expert Opin Pharmacother 13: 2397-2407, 2012

20. Weinberg R: The Biology of Cancer, Second Edition. Taylor \& Francis Group, 2013.

21. Han SY, Lee CO, Ahn SH, Lee MO, Kang SY, Cha HJ, Cho SY, Ha JD, Ryu JW, Jung H, et al: Evaluation of a multi-kinase inhibitor KRC-108 as an anti-tumor agent in vitro and in vivo. Invest New Drugs 30: 518-523, 2012.

22. Vyas D, O'Dell KM, Bandy JL and Boyce EG: Tofacitinib: The first janus kinase (JAK) inhibitor for the treatment of rheumatoid arthritis. Ann Pharmacother 47: 1524-1531, 2013.

23. Dolgin E: Companies hope for kinase inhibitor JAKpot. Nat Rev Drug Discov 10: 717-718, 2011.

24. Ratner M: Setback for JAK2 inhibitors. Nat Biotechnol 32: 119 , 2014. 